\title{
Emerging issues in paediatric health research consent forms in Canada: working towards best practices
}

Edward S Dove*, Denise Avard, Lee Black and Bartha M Knoppers

\begin{abstract}
Background: Obtaining a research participant's voluntary and informed consent is the bedrock of sound ethics practice. Greater inclusion of children in research has led to questions about how paediatric consent operates in practice to accord with current and emerging legal and socio-ethical issues, norms, and requirements.

Methods: Employing a qualitative thematic content analysis, we examined paediatric consent forms from major academic centres and public organisations across Canada dated from 2008-2011, which were purposively selected to reflect different types of research ethics boards, participants, and studies. The studies included biobanking, longitudinal studies, and gene-environment studies. Our purpose was to explore the following six emerging issues: (1) whether the scope of parental consent allows for a child's assent, dissent, or future consent; (2) whether the concepts of risk and benefit incorporate the child's psychological and social perspective; (3) whether a child's ability to withdraw is respected and to what extent withdrawal is permitted; (4) whether the return of research results includes individual results and/or incidental findings and the processes involved therein; (5) whether privacy and confidentiality concerns adequately address the child's perspective and whether standard data and/or sample identifiability nomenclature is used; and (6) whether retention of and access to paediatric biological samples and associated medical data are addressed.

Results: The review suggests gaps and variability in the consent forms with respect to addressing each of the six issues. Many forms did not discuss the possibility of returning research results, be they individual or general/aggregate results. Forms were also divided in terms of the scope of parental consent (specific versus broad), and none discussed a process for resolving disputes that can arise when either the parents or the child wishes to withdraw from the study.

Conclusions: The analysis provides valuable insight and evidence into how consent forms address current ethical issues. While we do not thoroughly explore the contexts and reasons behind consent form gaps and variability, we do advocate and formulate the development of best practices for drafting paediatric health research consent forms. This can greatly ameliorate current gaps and facilitate harmonised and yet contextualised approaches to paediatric health research ethics.
\end{abstract}

Keywords: Children, Confidentiality, Consent, ELSI, Paediatric research, Research ethics, Return of results, Withdrawal

\footnotetext{
* Correspondence: edward.dove@mail.mcgill.ca

Department of Human Genetics, Centre of Genomics and Policy, Faculty of Medicine, McGill University, 740 Avenue Dr. Penfield, Suite 5200, Montreal, QC H3A 0G1, Canada
}

\section{Ciomed Central}

(c) 2013 Dove et al.; licensee BioMed Central Ltd. This is an Open Access article distributed under the terms of the Creative Commons Attribution License (http://creativecommons.org/licenses/by/2.0), which permits unrestricted use, distribution, and reproduction in any medium, provided the original work is properly cited. 


\section{Background}

Obtaining a research participant's voluntary and informed consent is the bedrock of sound legal and ethics practice. From an ethical and human rights perspective, informed consent protects the research participant from potential harm and promotes his or her autonomy and dignity. From a legal perspective, it can act as a waiver to the common law tort of battery or negligence in medical research.

Children $^{\mathrm{a}}$ constitute an important population subgroup in health research, and their growing inclusion in research has led to questions about how paediatric consent operates in practice. This is partly attributable to an expanding body of evidence that indicates tremendous gaps, variability, and apparent inconsistency in the content of consent forms for health research, even for similar studies or at different sites within the same study [1-8]. This may be due to, in part, new challenges raised by health research that are not addressed or settled in current guidelines. Another reason, often stated by research ethics boards (REBs) themselves, may be sensitivity to local concerns of participant communities, administrations, and cultures [9]. While some flexibility and diversity is warranted, consent form variability and inconsistency should be scrutinised for several reasons. First, large-scale study forms that do not consider the growing importance that many significant research funders place on broad data sharing may impede data flow through varying modalities of consent, data or sample coding, and data or sample transfer policies [10]. Second, from an ethical viewpoint, inconsistency and a lack of harmonisation may unevenly protect research participants [11]. Third and most crucially, it can undermine the trust that parents ${ }^{\mathrm{b}}$, children, researchers and society place in research enterprises, and ultimately cause harm to children's rights [12,13].

Considering the rapid research developments in areas such as biobanking, longitudinal studies, gene-gene or gene-environment studies, and exome- or genome-wide association studies, it is important to examine the approaches in consent forms that address several key issues in paediatric research that the literature identifies as emerging [14-24], namely those arising under the domain of: (1) the scope of consent of the parent and/or child; (2) risks and benefits; (3) the right of withdrawal; (4) return of research results and incidental findings; (5) privacy and confidentiality; and (6) retention of and access to the child's data and/or samples.

These issues have significant impact on the content of the informed consent forms and its process. In response to the growing research in the field of paediatrics, we hope to draw attention to emerging ethical issues in paediatric research where further harmonisation could surface. Our objective in the first part of the analysis is a) to find out how much information refers to these emerging issues, and b) to evaluate the quality using a structured checklist based on the best practices. Since we noted a lack of consistency, in the second part, we propose some best practices for the development of the consent forms. This, we contend, is a pressing need because children are vulnerable and require protection [25], and because their specific health interests via research require promotion. Addressing the emerging issues in paediatric research consent forms will facilitate harmonised and yet contextualised approaches, hopefully promoting a safer and healthier world for children.

\section{Methods}

\section{Sample identification}

REB-approved assent and consent forms dated 2008-2011 for paediatric research from across Canada were collected. Members of Canada's Maternal Infant Child and Youth Research Network (MICYRN), which consists of 17 child health research organisations at academic health centres affiliated with universities or medical schools in Canada, were contacted and asked to provide copies of their REBapproved informed consent forms. In addition, we searched websites of large organisations engaged in paediatric research across Canada using our personal knowledge of ongoing research projects at leading hospitals and research institutes. By way of purposive sampling, we deliberately collected consent forms arising from observational, genetic, longitudinal, and clinical trial studies. Through the end of 2011, we collected and reviewed 65 forms.

Figure 1 depicts the inclusion and exclusion criteria. We excluded assent forms $(n=12)$ since they are addressed only to children, are somewhat distinct from consent forms, and will be the subject of a separate paper. We also excluded non-Canadian forms $(\mathrm{n}=6)$ and forms $(\mathrm{n}=4)$ that consisted only of research conducted with pregnant women and/or parents and not with neonates or children. The resulting data set consisted of 43 documents that met our inclusion criteria and addressed at least one of our emerging issues. They were selected from major academic research centres or public health organisations that included forms (with some overlap) for studies that included biobanks, clinical trials, longitudinal studies, observational studies, as well as paediatric research consent form templates $(\mathrm{n}=16)$ drafted by research institutions, hospitals, or government agencies.

\section{Data abstraction}

Following a modified qualitative thematic content analysis [26], the content of the consent forms was coded using an 'a priori' coding approach based on emerging issues falling under six domains (Figure 2). These domains were framed as determining whether: (1) the scope of parental consent allows for a child's assent, dissent, or future consent; (2) the concepts of risk and benefit incorporate the child's 


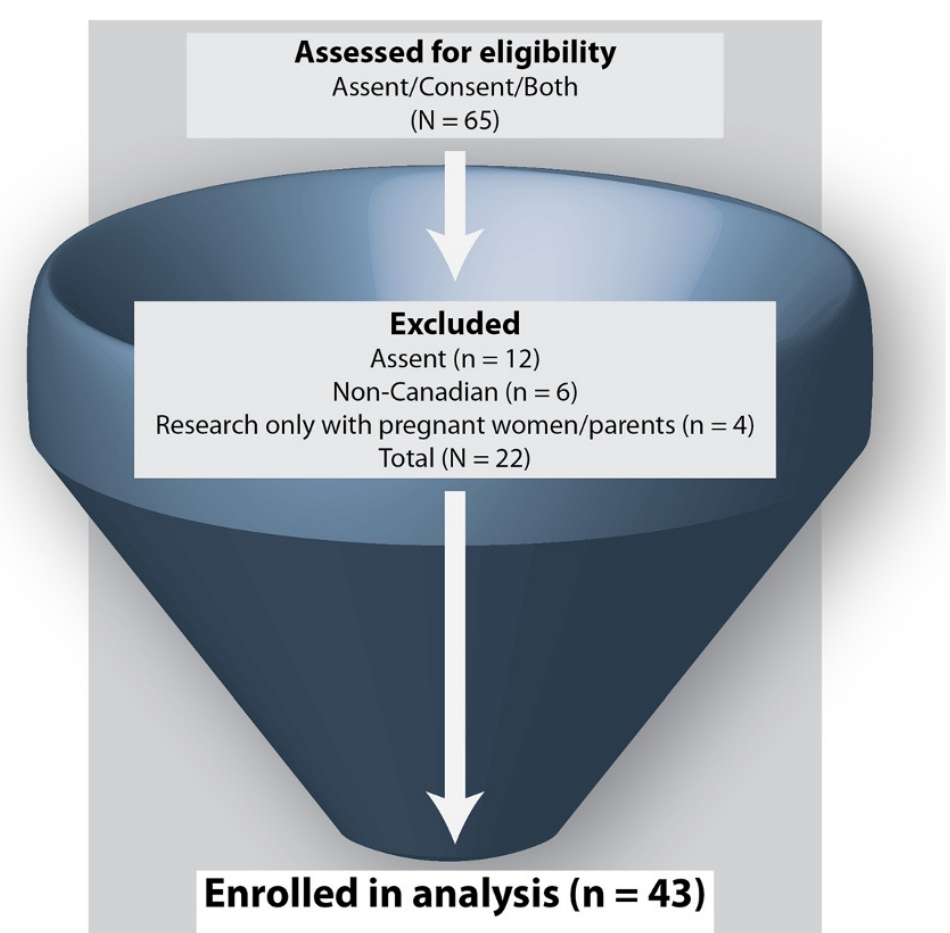

Characterized as including:

Biobanking $(\mathrm{n}=7)$

Clinical trial $(n=4)$

Genetic $(n=19)$

Longitudinal $(n=11)$

Observational $(n=17)$

Figure 1 Flow chart with the results of the search strategy.

\begin{tabular}{|c|c|}
\hline Scope of Parental Consent & $\begin{array}{l}\text { - Specific or broad consent } \\
\text { - Ability to dissent } \\
\text { - Ability to assent and/or provide future consent }\end{array}$ \\
\hline Risks and Benefits & $\begin{array}{l}\text { - Financial, social, and psychological issues as potential risks } \\
\text { - Cumulative harms considered in assessing individual harm } \\
\text { - How 'benefit' is characterised }\end{array}$ \\
\hline Extent of Withdrawal & $\begin{array}{l}\text { - Ability for child's withdrawal } \\
\text { - Extent of withdrawal } \\
\text { - Process for resolving potential informational entanglemen }\end{array}$ \\
\hline $\begin{array}{l}\text { Return of Research Results } \\
\text { and Incidental Findings }\end{array}$ & $\begin{array}{l}\text { - Policy for return of research results and incidental findings } \\
\text { - Process for return } \\
\text { - Who returns/contacts }\end{array}$ \\
\hline Privacy and Confidentiality & $\begin{array}{l}\text { - Parents' right to access information concerning their child } \\
\text { - Nomenclature for data/sample identifiability }\end{array}$ \\
\hline Transfer and Data Sharing & $\begin{array}{l}\text { - Retention period(s) of data/samples } \\
\text { - Access to data/samples }\end{array}$ \\
\hline
\end{tabular}

Figure 2 Summary of emerging issues in six domains. 
psychological and social perspective; (3) a child's ability to withdraw is respected and to what extent withdrawal is permitted; (4) the return of research results includes individual results and/or incidental findings and the processes involved therein; (5) privacy and confidentiality concerns adequately address the child's perspective and whether standard data and/or sample identifiability nomenclature is used; and (6) retention of and access to paediatric biological samples and associated medical data are addressed. These domains (and the sub-issues within each) were chosen to provide a benchmark by which to judge how the issues were addressed in the consent forms and because they represent, in our opinion and experience as paediatric health ethics researchers, the most debated and unresolved in the field. Two reviewers independently screened the consent forms (ESD and ML). Any discrepancies were reconciled and checked by another evaluator (DA). The analysis consisted of a review of the written information in the forms, which was extracted and presented in tables.

\section{Results}

The results of our research are summarised in Table 1 (see also Additional file 1).

\section{Consent}

Thirty percent of the forms used specific consent (i.e. the participant is informed in a detailed fashion of the research objectives, procedures, risks, benefits, and future uses of data and samples collected), while $42 \%$ used broad consent (i.e. the participant is informed that data and samples may be used in future, unspecified studies). The remainder either did not specify the scope, as they were template forms, or presented an option for specific or broad consent. Fifty-six percent of the forms did not address a child's ability to dissent; $49 \%$ of the forms addressed neither assent nor the potential for future reconsent at the legal age of majority, while $30 \%$ addressed assent with qualifications such as a specific age.

\section{Risks and benefits}

Only a quarter of the forms (25.6\%) addressed financial, social, or psychological issues in the context of potential risks. One form - a template - addressed all three issues. Three forms explicitly considered cumulative harms for the child participant. To classify 'benefit', we distinguished a direct benefit (i.e. a tangible positive outcome whereby there is an intervention intended to prevent, diagnose, or treat illness or injury) and indirect benefit (i.e. benefits to other children of the same age or with the same condition, or benefits that are not related to the research objectives as such that could include gifts or payments). Sixty-seven percent of the forms expressed indirect benefits to research participants, often in the form of altruistic notions of helping society benefit from greater knowledge of a particular disease or childhood development. One form related to a clinical genetic study indicated a direct benefit to the child. Two forms (in the context of clinical trials) indicated both a potential direct benefit to the child as well as indirect benefits to society or other paediatric patients in the future.

\section{Withdrawal}

Sixty-five percent of the forms addressed a child's possible ability to withdraw, none of which imposed qualifications such as demonstrable competence and maturity in making such a decision. Other forms, however, addressed the right to withdraw only to the parents and not to the child. For example, one consent form for a study to evaluate the safety and immunogenicity of a vaccine in children aged 6 months to 18 years stated that: 'Taking part in this study is entirely your choice. You may decide not to enrol your child and you may withdraw your child from the study at any time.' Indeed, no mention was made of the right of the child, even in adolescence or teenage years, to independently withdraw, and there was no assent form associated with this consent form in which such information could have been included. Regarding the extent of withdrawal, only $16 \%$ stated that all unused samples and/or data would be destroyed upon a request to withdraw; two forms stated that there would be no further use of the data and/or samples, and one stated that data collected up until the declaration of withdrawal would not be removed. None of the forms disclosed a process for handling informational entanglement', i.e. parental disagreement on withdrawal between themselves or with the mature minor.

\section{Return of research results and incidental findings}

Sixty percent of the consent forms addressed the possible return of research results. However, there was no consensus, with approximately $15 \%$ of the total number of forms each indicating: no return, return of general/aggregate results, or, of individual research results (including incidental findings), or, the return of both general/aggregate and individual research results. There were also various processes involved for the return, with some studies opting for a liaison with an independent laboratory to confirm an incidental finding, as well as providing the option of genetic counsellors to explain the implications of the finding. All of the forms addressing return of research results (other than a no return policy) revealed that the researchers would return the results, though one clinical trial form stated that the patient's doctor would possibly return individual results and incidental findings. Most of the genetic study or biobank consent forms that mentioned incidental findings stated that in addition to disclosure of research results by the researchers, participants had the option for 
Table 1 Emerging issues in paediatric research consent forms

\begin{tabular}{lll}
\hline $\begin{array}{l}\text { Emerging issues in paediatric research discussed } \\
\text { in consent forms }\end{array}$ & N total (43) & \% \\
\hline 1. Consent & & \\
\hline Scope of parental consent & 13 & 30 \\
\hline Specific & 18 & 42 \\
\hline Broad & 2 & 5 \\
\hline Broad or Specific (option) & 10 & 23 \\
\hline Not addressed & & \\
\hline Child's ability to dissent & 19 & 44 \\
\hline Addressed & 24 & 56 \\
\hline Not addressed & & \\
\hline Possibility for child's assent and/or future consent & 22 & 51 \\
\hline Assent or future consent addressed & 21 & 49 \\
\hline Neither addressed & & \\
\hline 2. Risks and benefits & 11 & 26 \\
\hline Financial, social or psychological issues as potential & & \\
\hline risks & 3 & 7 \\
\hline Cumulative harms considered & & \\
\hline How 'benefit' characterised & 11 & 26 \\
\hline Indirect & 3 & 7 \\
\hline Unspecified & & \\
\hline Direct or combination of direct/indirect & & \\
\hline 3. Extent of withdrawal & & \\
\hline
\end{tabular}

\section{Extent of withdrawal}

\section{Ability for child to withdraw}

\begin{tabular}{lll}
\hline Addressed & 28 & 65 \\
\hline Not addressed & 15 & 35 \\
\hline
\end{tabular}

Extent of withdrawal

\begin{tabular}{lll}
\hline All data/samples destroyed & 7 & 16 \\
\hline
\end{tabular}

\begin{tabular}{lll}
\hline No further use of data/samples & 1 & 2 \\
\hline
\end{tabular}

Retention of data/samples collected to date $\quad 3 \quad 74$

\begin{tabular}{lll}
\hline Not addressed or unspecified & 32 & 74 \\
\hline Process for handlng parentalchild disagreemen & 0 & 0
\end{tabular}

Process for handling parental-child disagreement on $0 \quad 0$ withdrawal

\begin{tabular}{|c|c|c|}
\hline \multicolumn{3}{|l|}{$\begin{array}{l}\text { 4. Return of research results and incidental } \\
\text { findings }\end{array}$} \\
\hline Not addressed & 17 & 40 \\
\hline Addressed & 26 & 60 \\
\hline No return & 6 & 14 \\
\hline General/aggregate results return & 7 & 16 \\
\hline Individual results return & 7 & 16 \\
\hline General/aggregate and individual results return & 6 & 14 \\
\hline $\begin{array}{l}\text { Any return of results that include incidental findings } \\
\text { (with or without option) }\end{array}$ & 8 & 19 \\
\hline
\end{tabular}

Table 1 Emerging issues in paediatric research consent forms (Continued)

\begin{tabular}{|c|c|c|}
\hline \multicolumn{3}{|l|}{ 5. Privacy and confidentiality } \\
\hline $\begin{array}{l}\text { Scope of parental right to access information } \\
\text { concerning their child }\end{array}$ & 0 & 0 \\
\hline \multicolumn{3}{|l|}{ Nomenclature for data/sample identifiability } \\
\hline Unspecified & 14 & 33 \\
\hline Coded & 25 & 58 \\
\hline Anonymised & 4 & 9 \\
\hline \multicolumn{3}{|l|}{ 6. Transfer and data sharing } \\
\hline \multicolumn{3}{|l|}{ Retention period(s) of data/samples } \\
\hline Indefinite & 12 & 28 \\
\hline Specified time periods & 18 & 42 \\
\hline $\begin{array}{l}\text { Combination of indefinite and specified time periods, } \\
\text { depending on whether material is data or samples }\end{array}$ & 4 & 9 \\
\hline Not addressed & 9 & 21 \\
\hline \multicolumn{3}{|l|}{ Access to data/samples } \\
\hline No transfer & 2 & 5 \\
\hline $\begin{array}{l}\text { Disclosure that data/samples may be transferred to } \\
\text { another location }\end{array}$ & 17 & 40 \\
\hline $\begin{array}{l}\text { Disclosure and discussion of procedure for external } \\
\text { data/sample transfer }\end{array}$ & 4 & 9 \\
\hline Not addressed & 20 & 47 \\
\hline
\end{tabular}

an independent genetic clinic to confirm test results and for genetic counsellors to discuss such findings or genetic test results.

\section{Privacy and confidentiality}

None of the forms disclosed any information about a parent's qualified or unqualified right to access information concerning their child, though indirectly related, one form discussed the situation of a child's pregnancy while enrolled. One-third of the forms did not specify a particular manner of protecting data and sample identifiability, other than a general statement of a commitment to keep all information confidential and protected, but 58\% used the word 'coded' for data and/or samples. Only 9\% stated that data and/or samples would be anonymised.

\section{Retention of and access to child's data and/or samples}

Forty-two percent of the forms disclosed that data/samples would be retained and disclosed the period of time (including if it was an indefinite period), or in the case of template forms, stated that researchers should specify the retention period(s). Twenty-eight percent stated that data/samples would be retained, but did not specify a period, while $9 \%$ disclosed that samples would be held for a period of time (in these cases, indefinitely), but did not specify a period for data retention. Lastly, $47 \%$ did not discuss whether data/samples would be transferred to another location (e.g. province, country) during or after the study. Forty percent disclosed that data/samples 
could be transferred to another location, and 9\% went beyond simple disclosure and also stated the transfer process of the data/samples. Two forms explicitly stated that there would be no transfer of data/samples outside of the study site.

\section{Discussion}

The results indicate incongruent approaches to addressing emerging issues, if indeed they are addressed at all. There are several explanations for this, and each issue may manifest different rationales for variability. With respect to consent, for example, it is generally accepted that the failure to address in some capacity a child's assent and then later consent as they mature (if the research project continues over a prolonged period) can undermine the integrity of the project and create schisms in the current and future protection of a child's wellbeing and developing autonomy. These issues are of particular importance in longitudinal and biobanking studies that intend to use samples and data indefinitely. But re-contact, perhaps in studies not specifically longitudinal in nature, may be regarded as unforeseen, unfeasible, or unrealistic. Hence, an explanation for the common implementation of 'broad consent' in the consent forms we reviewed may be that it is viewed as the most practical, efficient, and appropriate scope of consent, provided the samples and data are coded rather than anonymised so that re-contact is possible. It should be noted that broad consent was largely seen, as expected, in the longitudinal and biobanking research studies.

That the majority of the consent forms we analyzed did not address cumulative or non-physical risks may speak to the definitional ambiguity of 'risk' and the tendency to focus on physical risks. Risk is defined in Canada's 2010 Tri-Council Policy Statement (TCPS) [27] ${ }^{\mathrm{c}}$ as 'a function of the magnitude or seriousness of the harm, and the probability that it will occur' (TCPS, Ch. 2B), but this does not address the ambit of harm. In paediatric research, harm may encompass psychological, social, financial, and community risks, particularly in genetic, biobanking, and longitudinal research. This is more than an ethical concern. In Canada, full disclosure of risks in research is legally required $[28,29]$. Along the same lines, given that most forms stated that indirect benefits (e.g. a societal benefit from biomedical advancement) would be achieved, one must conclude that the research projects entailed no more than 'minimal risk' in order to receive REB approval, as required by the TCPS (Art. 4.6). Yet, it remains an open question whether these projects truly pose a minimal risk if they do not disclose non-physical risks, consider cumulative risks, or consider risks from the perspective of the child whose perspective may differ drastically depending on age [30].
The lack of specificity in some of the forms that the child could withdraw rather than the parent providing the authorisation, and the lack of a resolution procedure for withdrawal conflicts between children and parents, may be due to normative guidelines that generally encourage, rather than require, researchers to respect a child's decision to withdraw from research if the child has the capacity and maturity to make an independent choice [19,31]. The consent forms that failed to clearly state to the parents that withdrawal may not in fact be absolute could be due to instances where data and samples are irretrievably de-linked to an identifiable person (i.e. they are anonymised). Yet, almost no forms indicated anonymisation was involved, so this is only a partial explanation. This also leaves open the question as to whether parents or children are aware that should they later change their mind about participating in a study that has anonymised their data or samples, destruction of their data or samples is no longer possible as they cannot be identified.

The return of research results has garnered significant discussion, especially with the advent of whole genome and exome sequencing [20,32,33]. Incidental findings, defined as 'unanticipated discoveries made in the course of research but that are outside the scope of the research' (TCPS Article 3.4), are becoming increasingly important as data-intensive science expands and next generation sequencing technologies are employed [34,35]. Currently, there is neither national nor international consensus on the treatment of incidental findings in paediatrics, and the consent forms we reviewed reflect this variability and continuing lack of consensus, with respect to both return of research results and incidental findings. In cases where results reveal a clinically significant condition for which there is current treatment or prevention, the parents cannot refuse to know and the child's right to medical care prevails $[14,21,36]$. In other situations, researchers - and parents - may opt to wait until the child is mature enough or reaches majority before disclosing research results if the results are not materially relevant until the child reaches adulthood. Either way, the potential for these situations, especially if their possibility is known at the time of consent, should be explained in the consent form and further elaborated upon by the individual obtaining consent. Similarly, consent forms should be clear if the child's consent or assent to receiving the information would be sought so as to not compromise the child's 'right to an open future' [37], and if the 'right not to know' necessarily includes the right not to have information included in the medical record if it entails an actionable result.

It is a positive sign that most of the forms we analysed provided standardised nomenclature for sample or data identifiability (e.g. 'coded'), since terminological confusion has long been an issue [38]. However, standardised nomenclature may be seen as only the first step to 
addressing privacy and confidentiality concerns. Challenges to privacy and confidentiality are amplified by genomics and other biomedical research projects [39], which are often internationally collaborative and engage in perpetual data linkage across jurisdictions. Biobanking or genetic research consent forms may need to declare that neither anonymised nor coded data and samples can guarantee privacy, as knowledge of even a small number of genetic variants can lead to matching of samples to individuals with a high level of confidence (we did not observe consent forms that disclosed this potential privacy risk).

All of the consent forms assumed parents could access research-related information about their child. And yet, multiple tensions can arise between the child's privacy interests and the parents' general legal right to their child's health information [40-42]. For example, a child may not want her parents to know about a pregnancy test result or habitual drug use, but this desire could conflict with legal duties of parental access to health information that compel a researcher to disclose such information. At a minimum, consent forms should disclose the kind or extent of information communicated to the parent and information which shall require the child's consent.

Lastly, while ethical norms generally support transfer of data and samples with certain safeguards, there is continuing debate about the parameters of that transfer and the various organisational safeguards, technological measures, and physical measures that should be adopted and updated - and disclosed - in the consent form. Research participants remain woefully uninformed of the transfer of their samples and data, particularly when it may carry a commercial use [43]. Devising and disclosing a method for listing all approved projects that are accessing the data and/or samples could alleviate this. While it may be the case that all of the consent forms we analysed that did not address transfer of data and samples simply did not envision transfer, in the absence of explicit disclosure that 'no transfer will occur', uncertainty remains and creates the risk of future ethical concerns with maturing children.

\section{Study limitations}

Our study had some limitations. It relied on our purposive sampling derived from Canada, which may not be generalisable to other countries. Our data focuses on emerging ethical issues rather than on the context of the consent process or on the quality of consent form information and its actual comprehension by participants. These are two critically important topics discussed elsewhere in the literature [44-46]. Similarly, the amount and quality of information extracted from the consent forms regarding these six issues cannot provide an estimated average that is generalisable to all consent forms, though the range of issues in our purposive sampling reveals important gaps. Some types of consent forms may have been underrepresented, such as qualitative research or community setting research. There are other emerging issues impacting the consent process that were not considered in this study due to resource constraints, but are worthy of future reviews, such as the issue of incentives for participating in research. This is an area that is rapidly becoming a point of controversy; offering monetary payments, gift certificates, or toys to parents or children who participate in research touch on ethical issues of undue influence and voluntariness [47-50]. Despite these limitations, this research addresses important gaps in the literature by incorporating evidence regarding emerging ethical issues that will in turn improve the usefulness of paediatric consent forms.

\section{Towards best practices}

As our Discussion section notes, divergence in these six distinct domains in paediatric research reflects various factors. The rapidly evolving nature of science and technology can hamper the ability of researchers and REBs to keep abreast of socio-ethical discourse surrounding the inclusion of various types of emerging issue information. But, it is insufficient to only identify problem areas and explanations in the current environment. Remedies should be offered as well. Therefore, we suggest some best practices that can improve consent forms and facilitate harmonised and yet contextualised approaches to ethical norms in paediatric research.

We opt for best practices deliberately. In the modern, diverse research environment, where there is a plethora of possibilities (sometimes overlapping), not all paediatric research is alike. Designing a standard template for consent forms other than for the most basic provisions would restrict the flexibility needed to accommodate scientific developments and local contexts [39]. Best practices, however, can serve as useful general guidance to researchers when they design their paediatric research projects and draft consent forms. They can also help make REBs more aware of key issues and better scrutinise consent forms for ethical compliance, and can help ensure REBs maintain a flexible and innovative approach to template consent forms. A set of best practices can encourage dialogue between REBs and researchers to ensure that each informs the other of emerging issues and to not rigidly adhere to document templates for wording and formatting. Finally, best practices can help catalyse the growing importance of paediatric research and serve as a blueprint for further development of standards and guidance, such as online educational and practical tools to enhance understanding of the emerging issues.

Building on the Best Practices for Health Research Involving Children and Adolescents [14], we propose a non-exhaustive list of what we consider to be best 
Table 2 Best practices for drafting paediatric research consent forms in Canada

\begin{tabular}{|c|c|}
\hline Emerging issue & Best practices \\
\hline \multicolumn{2}{|l|}{ Scope of parental consent } \\
\hline Broad consent & $\begin{array}{l}\text { - The possibility of future, unspecified research uses should be mentioned prior to obtaining } \\
\text { consent and the consent form should be worded accordingly. }\end{array}$ \\
\hline \multirow[t]{2}{*}{ Ability to assent/provide future consent } & $\begin{array}{l}\text { - When the child is considered to be legally able to provide consent, consent should be } \\
\text { renewed, if feasible. }\end{array}$ \\
\hline & $\begin{array}{l}\text { - Where feasible, data and/or samples should be coded (not anonymised) in order to allow } \\
\text { researchers to maintain contact with the child. }\end{array}$ \\
\hline Ability to dissent & $\begin{array}{l}\text { - The possibility of a child's right to dissent, provided there is an ability to understand the } \\
\text { significance of research or his/her role in it, should be disclosed. }\end{array}$ \\
\hline \multicolumn{2}{|l|}{ Risks and benefits } \\
\hline Financial, social, and psychological issues & $\begin{array}{l}\text { - Consideration of potential harms must include physical as well as psychological, social or } \\
\text { financial harms. }\end{array}$ \\
\hline $\begin{array}{l}\text { Cumulative harms considered in assessing } \\
\text { individual harms }\end{array}$ & - Cumulative harms should be considered. \\
\hline How 'benefit' is characterised & - Risks and benefits should be considered from the child's perspective. \\
\hline \multicolumn{2}{|l|}{ Withdrawal } \\
\hline Ability for withdrawal & $\begin{array}{l}\text { - The child's ability to withdraw should be explicitly disclosed, as well as any circumstances that } \\
\text { might limit the ability (e.g. if immediate withdrawal could harm the child). }\end{array}$ \\
\hline Extent of withdrawal & $\begin{array}{l}\text { - The extent of the ability to withdraw should be explicitly disclosed (e.g. if data and/or samples } \\
\text { are anonymised, the consent form should state that withdrawal is not feasible). }\end{array}$ \\
\hline Informational entanglement & $\begin{array}{l}\text { - The potential for a child and parents to disagree about whether to withdraw, and its potential } \\
\text { impact on the research project, should be described. }\end{array}$ \\
\hline \multicolumn{2}{|l|}{$\begin{array}{l}\text { Return of research results and incidental } \\
\text { findings }\end{array}$} \\
\hline $\begin{array}{l}\text { The potential and process for returning research } \\
\text { results and incidental findings }\end{array}$ & $\begin{array}{l}\text { - The potential for disclosing research results and incidental findings, as well as its process } \\
\text { (including who discloses and the possibility for entitlement to non-disclosure), should be } \\
\text { described. }\end{array}$ \\
\hline $\begin{array}{l}\text { Returning actionable individual results and } \\
\text { incidental findings }\end{array}$ & $\begin{array}{l}\text { - Individual research results and incidental findings that have clinical significance should be } \\
\text { communicated to the child and/or parents when either prevention or treatment is available } \\
\text { during childhood, and with adequate counselling provided. The interconnected nature of the } \\
\text { potential risks and benefits of such communication should be disclosed. }\end{array}$ \\
\hline Duty to receive information & $\begin{array}{l}\text { - Parents should be made aware that they will receive clinically significant information about } \\
\text { conditions that are preventable or treatable during childhood. }\end{array}$ \\
\hline \multicolumn{2}{|l|}{ Privacy and confidentiality } \\
\hline $\begin{array}{l}\text { Parents' right to access information concerning } \\
\text { their child }\end{array}$ & $\begin{array}{l}\text { - In research projects that collect and use particularly sensitive information, such as pregnancy } \\
\text { status, drug use, or sexual history, consent forms should disclose what information will and will } \\
\text { not be communicated to parents, and which information disclosure requires the child's consent. }\end{array}$ \\
\hline \multirow[t]{2}{*}{ Nomenclature for data/sample identifiability } & $\begin{array}{l}\text { - Standardised sample identifiability terminology should be used: coded (including single-coded } \\
\text { and double-coded), anonymised, and anonymous. }\end{array}$ \\
\hline & $\begin{array}{l}\text { - Biobanking or genetic research consent forms should declare that anonymised or coded data } \\
\text { and samples cannot absolutely guarantee privacy. }\end{array}$ \\
\hline \multicolumn{2}{|l|}{ Retention of and access to data/samples } \\
\hline Retention period(s) of data/samples & $\begin{array}{l}\text { - Consent forms should clearly distinguish between what is a legally required data/sample } \\
\text { retention period and a retention period decided upon by the researcher. }\end{array}$ \\
\hline \multirow[t]{3}{*}{ Access to data/samples } & - The policies and procedures for access to data and/or samples should be disclosed. \\
\hline & $\begin{array}{l}\text { - These policies and procedures should consider the privacy impact (both to the parents and } \\
\text { child) of access to coded or anonymised information, including: organisational safeguards, } \\
\text { technological measures, physical measures, and ethics oversight. }\end{array}$ \\
\hline & $\begin{array}{l}\text { - If feasible, researchers should disclose a method for listing all approved projects that are } \\
\text { accessing the data and/or samples. }\end{array}$ \\
\hline
\end{tabular}


practices for drafting consent forms that address the emerging issues discussed in this article (Table 2).

\section{Conclusions}

This article assesses Canadian paediatric consent forms in light of emerging ethical issues in paediatric consent practices and identifies many gaps and inconsistencies among the forms. Attention to the best practices could make a big difference. To this end, we acknowledge that informed consent is infinitely more complex than ethics guidelines or law imply. The more those in the research community recognise that information disclosed to a participant depends on context (e.g. study project, location, resources) and must go beyond mere duties of disclosure to actually achieve understanding [51], the further researchers and REBs can move towards ensuring there is genuine research participation, and indeed, engagement [52-54]. To help get there, future research should couple a thematic analysis of paediatric consent or assent forms with surveys of views and experiences of parents and children so as to offer a more holistic approach to evaluating the strengths and weaknesses of these forms.

At the same time, consent forms cannot and should not include all issues under the sun, lest information overload ensue. More information is not always better information; indeed, consent form length may not materially affect the quality of informed consent or consent rate $[55,56]$. While some may perceive these best practices as cumbersome additions to already unwieldy consent forms, appreciation for contextualisation and brevity must be distinguished from inappropriate omissions or unreasonable and unpredictable ethical standards. We hope that the best practices listed in Table 2 will be a useful guide for both the drafters of consent forms and for REBs.

Ultimately, organisations, funding agencies, as well as researchers and REBs, must work together to develop a well-forged, dynamic ethical and legal toolbox to ensure that consent forms disclose a sufficiently uniform level of understandable information, including potentially contentious issues, so that parents and children (to the extent they are capable) can make an informed decision together [57]. Attention to best practices will improve research collaboration, provide workable tools for researchers and ethics boards, and improve the ethical tensions that can occur in the tri-partite relationship between the child, parents, and researchers. This enables us to ensure that the most important participants in this process - children are fully protected, respected and given the opportunity to grow up in a healthier and safer world.

\section{Endnotes}

${ }^{a}$ For this article, we adopt the definition of 'child' in Article 1 of the UN Convention on the Rights of the Child (1989): ' . . . a child means every human being below the age of eighteen years unless under the law applicable to the child, majority is attained earlier.'

b For this article, 'parent(s)' also includes legal representative(s) and legal guardian(s).

${ }^{c}$ Paediatric researchers and their institutions who receive funds from the three major Canadian federal funding agencies (Canadian Institutes of Health Research, Sciences and Engineering Research Council, and Social Sciences and Humanities Research Council) must ensure that their consent forms conform to ethical standards established by the TCPS. Certain health and social service institutions in provinces also have policies endorsing the TCPS (e.g. the Ministère de la Santé et des Services sociaux du Québec).

\section{Additional file}

Additional file 1: Table of results for consent forms in addressing emerging issues.

\section{Abbreviations}

MICYRN: Maternal Infant Child and Youth Research Network; REB: Research ethics board; TCPS: Tri-Council Policy Statement.

\section{Competing interests}

The authors have no competing interests.

\section{Authors' contributions}

All authors conceived the study and participated in its design. LB, DA, and BMK collected the raw data. ESD, LB, and DA coded the data. BMK helped in the coordination of the study. ESD, LB, and DA performed data analysis. ESD drafted the manuscript. All authors were involved in the editing. All authors have read and approved the final manuscript.

\section{Ethical approval}

No ethical approval was sought in connection with the study as, in accordance with Canadian ethics guidelines, there was no research involving human subjects or research on information containing personally identifiable information.

\section{Acknowledgements}

The authors wish to thank Michael Le Huynh (ML) and Amy Dam (AD) for their valuable research assistance in collecting the raw data and in the preparation of this manuscript. The authors also wish to thank the Maternal Infant Child and Youth Research Network (MICYRN); the International Cancer Genome Consortium (ICGC); and the Finding of Rare Disease Genes in Canada Project (FORGE) (Genome Canada/CIHR) for research funding. The authors also wish to thank Jean-François Ouellette for his assistance in the preparation of the figures.

Received: 15 June 2012 Accepted: 29 October 2012

Published: 30 January 2013

\section{References}

1. Matheson LA, Huber AM, Warner A, Rosenberg AM: Towards harmonization of pediatric research ethics review protocols among Canadian institutions: a Canadian pediatric rheumatology experience. Paediatr Child Health 2012, 17:313-316.

2. Palmour N, Affleck W, Bell E, Deslauriers C, Pike B, Doyon J, Racine E: Informed consent for MRI and $\mathrm{fMRI}$ research: analysis of a sample of Canadian consent documents. BMC Med Ethics 2011, 12:1.

3. Allen C, Foulkes WD: Qualitative thematic analysis of consent forms used in cancer genome sequencing. BMC Med Ethics 2011, 12:14.

4. Al-Riyami A, Jaju D, Jaju S, Silverman HJ: The adequacy of informed consent forms in genetic research in Oman: a pilot study. Dev World Bioeth 2011, 11:57-62. 
5. Padhy BM, Gupta P, Gupta YK: Analysis of the compliance of informed consent documents with good clinical practice guideline. Contemp Clin Trials 2011, 32:662-666.

6. McWilliams R, Hoover-Fong J, Hamosh A, Beck S, Beaty T, Cutting G: Problematic variation in local institutional review of a multicenter genetic epidemiology study. JAMA 2003, 290:360-366.

7. Stair TO, Reed CR, Radeos MS, Koski G, Camargo CA, MARC Investigators: Variation in institutional review board responses to a standard protoco for a multicenter clinical trial. Acad Emerg Med 2001, 8:636-641.

8. Silverman HJ, Hull SC, Sugarman J: Variability among institutional review boards' decisions within the context of a multicenter trial. Crit Care Med 2001, 29:235-241.

9. Klitzman R, Appelbaum PS: To protect human subjects, review what was done, not proposed. Science 2012, 335:1576-1577.

10. McGuire AL, Basford M, Dressler LG, Fullerton SM, Koenig BA, Li R, McCarty CA, Ramos E, Smith ME, Somkin CP, Waudby C, Wolf WA, Clayton EW: Ethical and practical challenges of sharing data from genome-wide association studies: the eMERGE Consortium experience. Genome Res 2011, 21:1001-1007.

11. Caulfield T, Ries N, Barr G: Variation in ethics review of multi-site research initiatives. Amsterdam Law Forum 2011, 3:85-100.

12. Blake $V$, Joffe $S$, Kodish E: Harmonization of ethics policies in pediatric research. J Law Med Ethics 2011, 39:70-78.

13. Lambert V, Glacken M: Engaging with children in research: Theoretical and practical implications of negotiating informed consent/assent. Nurs Ethics 2011, 18:781-801

14. Canadian Institutes of Health Research (CIHR), Avard D, Black L, Samuël J, Griener G, Knoppers BM: Best Practices for Health Research Involving Children and Adolescents. http://www.genomicsandpolicy.org/best-practices.html.

15. Samuël J, Ries NM, Malkin D, Knoppers BM: Biobanks and longitudinal studies: where are the children? GenEdit 2008, 6:1-8.

16. Avard D, Samuël J: Knoppers BM (eds): Paediatric Research in Canada. Montréal: Les Éditions Thémis; 2009

17. Swartling U, Helgesson G, Hansson MG, Ludvigsson J: Split views among parents regarding children's right to decide about participation in research: a questionnaire survey. J Med Ethics 2009, 35:450-455.

18. Knoppers BM, Avard D, Thorogood A: Informed consent in genetics. eLS, in press.

19. Holm S: Informed consent and the bio-banking of material from children. Genomics Soc Policy 2005, 1:16-26.

20. Avard D, Sénécal K, Madadi $P$, Sinnett D: Pediatric research and the return of individual research results. J Law Med Ethics 2011, 39:593-604.

21. Knoppers BM: Paediatric research and the communication of not-so incidental findings. Paediatr Child Health 2012, 17:190-192.

22. Kaufman D, Geller G, Leroy L, Murphy J, Scott J, Hudson K: Ethical implications of including children in a large biobank for geneticepidemiologic research: a qualitative study of public opinion. Am J Med Genet C Semin Med Genet 2008, 148C:31-39.

23. Hens K, Nys H, Cassiman JJ, Dierickx K: Genetic research on stored tissue samples from minors: a systematic review of the ethical literature. Am Med Genet A 2009, 149A:2346-2358.

24. Dove ES, Black L, Avard D, Knoppers BM: Privacy in Canadian paediatric biobanks: a changing landscape. A report delivered to the Office of the Privacy Commissioner of Canada. http://www.humgen.org/int/Gl/

Privacy_in_Canadian_paediatric_Biobanks.pdf.

25. A.B. v. Bragg Communications Inc. 2012. 2012 SCC 46 (Supreme Ct. of Canada).

26. Neuendorf KA: The Content Analysis Guidebook. Thousand Oaks: Sage Publications; 2002

27. 2nd Edition of the Tri-Council Policy Statement: Ethical Conduct for Research Involving Humans. http://www.pre.ethics.gc.ca/pdf/eng/tcps2/ TCPS_2_FINAL_Web.pdf.

28. Halushka v. University of Saskatchewan. 1965. 53 D.L.R. (2d) 436 (Sask. Ct. of Appeal).

29. Weiss v. Solomon. 1989. 48 CCLT 280 (Que. Sup. Ct.)

30. Gammelgaard A, Bisgaard H: Seven-year-old children's perceptions of participating in a comprehensive clinical birth cohort study. Clin Ethic 2009, 4:79-84

31. Ries NM: Growing up as a research subject: ethical and legal issues in birth cohort studies involving genetic research. Health Law J 2007 15:1-41.

32. Zawati MH, Knoppers BM: International normative perspectives on the return of individual research results and incidental findings in genomic biobanks. Genet Med 2012, 14:484-489.
33. Knoppers BM, Levesque E: Return of research results: how should research results be handled? J Law Med Ethics 2011, 39:575-576.

34. Thorogood A, Knoppers B, Dondorp W, de Wert G: Whole-genome sequencing and the physician. Clin Genet 2012, 81:511-513.

35. Wilfond BS, Carpenter $\mathrm{KJ}$ : Incidental findings in pediatric research. J Law Med Ethics 2008, 36:332-340.

36. Hens K, Nys H, Cassiman J, Dierickx K: The return of individual research findings in paediatric genetic research. J Med Ethics 2011, 37:179-183.

37. Davis DS: Genetic dilemmas and the child's right to an open future. Rutgers Law J 1997, 28:549-592.

38. Knoppers BM, Saginur M: The Babel of genetic data terminology. Nat Biotechnol 2005, 23:925-927.

39. Boddington P, Curren L, Kaye J, Kanellopoulou N, Melham K, Gowans H, Hawkins N: Consent forms in genomics: the difference between law and practice. Eur J Health Law 2011, 18:491-519.

40. Fisher CB: Privacy and ethics in pediatric environmental health researchpart I: genetic and prenatal testing. Environ Health Perspect 2006 114:1617-1621.

41. Helseth S, Slettebø A: Research involving children: some ethical issues. Nurs Ethics 2004, 11:298-308.

42. Shmueli B, Blecher-Prigat A: Privacy for children. Columbia Human Rights Law Rev 2011, 42:759-795.

43. Lenk C, Beier K: Is the commercialisation of human tissue and body material forbidden in the countries of the European Union? J Med Ethics 2012, 38:342-346.

44. O'Lonergan TA, Forster-Harwood JE: Novel approach to parental permission and child assent for research: improving comprehension. Pediatrics 2011, 127:917-924.

45. Ménoni V, Lucas N, Leforestier JF, Doz F, Chatellier G, Jacqz-Aigain E, Giraud C, Tréluyer JM, Chappuy $H$ : Readability of the written study information in pediatric research in France. PLoS One 2011, 6:e18484.

46. Wanzer MB, Wojtaszczyk AM, Schimert J, Missert L, Baker S, Baker R, Dunkle B: Enhancing the "informed" in informed consent: a pilot test of a multimedia presentation. Health Commun 2010, 25:365-374.

47. Wendler D, Rackoff JE, Emanuel EJ, Grady C: The ethics of paying for children's participation in research. J Pediatr 2002, 141:166-171.

48. Fernhoff PM: Paying for children to participate in research: a slippery slope or an enlightened stairway? J Pediatr 2002, 141:153-154.

49. Iltis AS, DeVader S, Matsuo H: Payments to children and adolescents enrolled in research: a pilot study. Pediatrics 2006, 118:1546-1552.

50. Bagley SJ, Reynolds WW, Nelson RM: Is a "wage-payment" model for research participation appropriate for children? Pediatrics 2007, 119:46-51

51. Manson NC, O'Neill O: Rethinking Informed Consent in Bioethics. Cambridge: Cambridge University Press; 2007.

52. Corrigan O: Empty ethics: the problem with informed consent. Sociol Health IIIn 2003, 25:768-792.

53. Henderson GE: Is informed consent broken? Am J Med Sci 2011, 342:267-272.

54. Pollock K: Procedure versus process: ethical paradigms and the conduct of qualitative research. BMC Med Ethics 2012, 13:25.

55. Matsui K, Lie RK, Turin TC, Kita Y: A randomized controlled trial of short and standard-length consent forms for a genetic cohort study: is longer better? J Epidemiol 2012, 22:308-316.

56. Schwartz V, Appelbaum PS: Improving the quality of informed consent to research. IRB 2008, 30:19-20.

57. Gibson BE, Stasiulis E, Gutfreund S, McDonald M, Dade L: Assessment of children's capacity to consent for research: a descriptive qualitative study of researchers' practices. J Med Ethics 2011, 37:504-509.

doi:10.1186/1472-6939-14-5

Cite this article as: Dove et al: Emerging issues in paediatric health research consent forms in Canada: working towards best practices. BMC Medical Ethics 2013 14:5. 